\section{Interspecific Relationships in Pistacia Based on RAPD Fingerprinting}

\author{
Salih Kafkas ${ }^{1}$ \\ University of Çukurova, Faculty of Agriculture, Department of Horticulture, \\ 01330 Adana, Turkey
}

Rafael Perl-Treves

University of Bar Ilan, Faculty of Life Sciences, 52900 Ramat Gan, Israel

Additional index words. Pistacia (Anacardiaceae), phylogeny, RAPD, fingerprinting, taxonomy

\begin{abstract}
Phylogenetic relationships among nine species in the genus Pistacia were studied by randomly amplified polymorphic DNA (RAPD) analysis. The following species were included: $P$. atlantica, $P$. terebinthus, $P$. eurycarpa, $P$. vera, $P$. integerrima, $P$. mexicana, $P$. palaestina, $P$. lentiscus, and $P$. khinjuk. Genomic DNA was extracted from leaf tissue and RAPD analysis was performed using 20 primers. A total of 242 fragments were generated and 228 bands were polymorphic at the inter-specific level. Subjecting these data to phylogenetic analysis yielded a shortest cladogram that is 338 steps long, featuring two main groups. $P$. vera, $P$. khinjuk, $P$. eurycarpa, $P$. atlantica, and $P$. integerrima were included in one group, while $P$. terebinthus, $P$. palaestina, $P$. mexicana, and $\boldsymbol{P}$. lentiscus formed the second group. The first group included species with single-trunked and big trees, whereas the species included in the second group mostly grow as shrubs or small trees. The cladogram showed that the closest pairs of species were $P$. terebinthus and $P$. palaestina, $P$. eurycarpa and $P$. atlantica, $P$. vera and $P$. khinjuk, and $P$. mexicana and $P$. lentiscus. We suggest that $P$. palaestina is in fact a variety of $P$. terebinthus in view of the small genetic distance between them. This study also showed that $P$. eurycarpa (syn. $P$. atlantica var. kurdica) is a distinct species from $P$. atlantica, rather than a variety within the same species.
\end{abstract}

Studies on the phylogeny of the genus Pistacia L. (Anacardiaceae) are rather few, and are mostly based on morphological characterization. The first monographic study of the genus was made by Engler (Zohary, 1952) who listed eight species and a few varieties. After Engler, several species have been added by different authors. So far, the most complete taxonomic study was done by Zohary (1952), who included 11 species in the genus Pistacia and divided them into four sections: 1) Section Lenticella Zoh.- P. mexicana HBK, $P$. texana Swingle; 2) Section Eu-Lentiscus Zoh.-P. lentiscus L., P. weinmannifolia Poisson, P. saportae Burnat; 3) Section Butmela Zoh.-P. atlantica Desf.; and 4) Section Eu-terebinthus-P. terebinthus L., $P$. palaestina Bois., $P$. khinjuk Stocks, $P$. vera $\mathrm{L}$., and $P$. chinensis Bge. Following Zohary, several other authors described and classified Pistacia species based on their morphology. Yaltirik (1967a) classified Pistacia species in Turkey and added a new species, $P$. eurycarpa Yalt., that had been designated as $P$. atlantica var. kurdica by Zohary (1952). Kafkas and Perl-Treves (2001) suggested, based on morphological and molecular evidence, that $P$. eurycarpa is a close relative of $P$. atlantica, but is a different species. Zohary considered $P$. palaestina as a

Received for publication 14 Nov. 2000. Accepted for publication 9 May 2001. We thank to D.E. Parfitt for providing $P$. khinjuk samples.

${ }^{1}$ To whom reprint requests should be addressed. separate species, whereas Yaltirik (1967a) retained it as a variety of $P$. terebinthus. Zohary (1972) described five Pistacia species in Israel. Grundwag and Werker (1976) described wood anatomy of Pistacia species in Israel, and Dong and Baas (1993) performed a similar study in China. Al-Yafi (1978) divided $P$. atlantica into four subspecies according to their leaf morphology. Kokwaro and Gillet (1980) described a new Pistacia species in East Africa, P. aethiopica Kokwaro, based on leaf morphology and tree size. The latter authors considered this species to be synonymous with $P$. lentiscus var. emarginata Engl., or a variety of $P$. atlantica. Lin et al. (1984) characterized leaf morphology, photosynthesis and leaf conductance of nine Pistacia species. El-Oqlah (1996) described Pistacia species in Jordan morphologically and anatomically.

Among these species, Pistacia vera, the pistachio, has edible nuts and commercial importance. The other species grow in the wild and their seeds are used mainly as a rootstock seed source and rarely used for fresh consumption, oil extraction, and soap production. All Pistacia species are dioecious and windpollinated. $P$. vera is believed to be the most ancestral species and the other species are probably its derivatives (Zohary, 1952). There are two centers of diversity of Pistacia: one comprises the Mediterranean region of Europe, Northern Africa, and the Middle East countries. The second comprises the Eastern part of Zagros mountains from Crimea to the
Caspian Sea. Pistachio cultivation extended westward from its center of origin to Italy, Spain, and other Mediterranean regions of Southern Europe, North Africa, and the Middle East, as well as eastward to China, and more recently to the United States and Australia (Hormaza et al., 1994, 1998; Maggs, 1973). Currently, Iran, United States, Turkey, and Syria are the main pistachio producers in the world, contributing over $90 \%$ of the world production (FAO 2000).

Molecular studies addressing the genus Pistacia are few. The pollen isozyme patterns of nine different enzymes were studied by Louskas and Pontikis (1979) in P. vera, $P$. terebinthus and $P$. lentiscus, to assay their inter-specific relationships. They found a closer phylogenetic relationship between $P$. vera and $P$. terebinthus than between $P$. vera and $P$. lentiscus. In our previous study (Kafkas and Perl-Treves, 2001), we mainly focused on the intra-specific relationship in the germplasm of three species (P. atlantica, P. terebinthus, and $P$. eurycarpa). Parfitt and Badenes (1997) were the first to provide a classification of 10 Pistacia species at the molecular level, and characterized these species based on chloroplast DNA profiles and subdivided the genus into two sections, 'Terebinthus' ( $P$. vera, $P$. khinjuk, $P$. atlantica, $P$. integerrima, $P$. chinensis, $P$. terebinthus) and 'Lentiscus' (P. mexicana, P. texana, P. weinmannifolia, $P$. lentiscus). The latter authors could not discriminate $P$. vera from $P$. khinjuk, and $P$. texana from $P$. mexicana. In the present study, we aimed to clarify the taxonomic relationships among nine species in the genus Pistacia by RAPD analysis, which targets the nuclear rather than organellar genome. Two of the species, $P$. palaestina and $P$. eurycarpa, were not included in the study of Parfitt and Badenes (1997).

\section{Materials and Methods}

Plant material. Plant material for this study was collected from three different countries: Turkey, Israel, and the United States (Table 1).

Genomic DNA extraction and RAPD reactions. Leaf samples were collected from a single representative accession per species, frozen in liquid nitrogen and stored at $-70{ }^{\circ} \mathrm{C}$ until use. Genomic DNA was extracted from leaf tissue by the CTAB method of Doyle and Doyle (1987) with minor modifications (Kafkas and Perl-Treves, 2001).

Randomly amplified polymorphic DNA (RAPD) analysis was performed according to Williams et al. (1990) with minor modifications. Amplification reactions were carried out in a $25 \mu \mathrm{L}$ volume containing $10 \mathrm{~mm}$ Tris$\mathrm{HCl}, \mathrm{pH} 9.0,50 \mathrm{~mm} \mathrm{KCl}, 1.5 \mathrm{~mm}^{\mathrm{MgCl}_{2}}$, $0.1 \%$ Triton $\mathrm{X}-100,0.2 \mu \mathrm{M}$ primer, $100 \mu \mathrm{M}$ each of dATP, dGTP, dCTP and dTTP, 1 unit of Taq DNA polymerase and $10 \mathrm{ng}$ of genomic DNA. Each reaction mixture was overlaid with mineral oil. DNA reactions were performed in a PTC-100 thermal cycler (MJResearch, Watertown, Mass.). The program included 1 cycle of 2 min at $94^{\circ} \mathrm{C}$, followed by 35 cycles of $45 \mathrm{~s}$ at $94{ }^{\circ} \mathrm{C}, 1 \mathrm{~min}$ at $36^{\circ} \mathrm{C}$, and 
Table 1. List of the plant materials used in this study

\begin{tabular}{|c|c|c|c|c|c|c|}
\hline$\overline{\text { Species }}$ & No. & Country & Accession no. & Province & County & Village \\
\hline P. eurycarpa & 1 & Turkey & $56-\mathrm{K}-07$ & Siirt & Aydinlar & Ikizbaglar \\
\hline P. atlantica & 1 & Turkey & $01-\mathrm{A}-04$ & Adana & Center & Kuyumcular \\
\hline P. terebinthus & 3 & Turkey & 09-T-02 & Adana & Center & Balcali \\
\hline P. integerrima & 1 & Turkey & PI-006 & Adana & Univ. of Çukurova & \\
\hline P. vera & 1 & Turkey & Cv Siirt & Gaziantep & Pistachio Research Institute & \\
\hline P. palaestina & 3 & Israel & --- & Jerusalem hills & & \\
\hline P. lentiscus & 1 & Israel & --- & Jerusalem hills & & \\
\hline P. khinjuk & 1 & USA & No:7 & Dr. Parfitt, Univ. of California, Davis & & \\
\hline P. mexicana & 1 & USA & DPIS0027 & $\begin{array}{c}\text { National Clonal Germplasm Repository, } \\
\text { USDA-ARS, Davis, Calif. }\end{array}$ & & \\
\hline
\end{tabular}

2 min at $72{ }^{\circ} \mathrm{C}$, for denaturing, annealing and primer extension, respectively. The last cycle was followed by a final incubation for $5 \mathrm{~min}$ at $72{ }^{\circ} \mathrm{C}$ and the PCR products were stored at 4 ${ }^{\circ} \mathrm{C}$ prior to analysis. Amplification products were analyzed by gel electrophoresis in $1.8 \%$ agarose in $1 \times$ TBE buffer, stained with ethidium bromide and photographed under UV light. From a preliminary screen of 200RAPD primers, the 20 most polymorphic primers (Univ. of British Colombia primers \#147, 165, 189, $302,304,308,319,322,327,338,345,346$, $348,353,354,356,376,381,383,396)$ were selected and used for fingerprinting and characterization of the nine Pistacia species.

Band scoring and parsimony analysis. Only the most clear and strong bands were used for phylogenetic analysis. Reproducibility of the patterns was tested by running the reactions in duplicates or in triplicates. Parsimony analysis was performed using the PAUP 3.1 program (Swofford, 1993) with different Heuristic search-options, and a $50 \%$ majority rule consensus tree was constructed from 100 bootstrap replicates of the same data. In addition, pair-wise genetic distances between all pair-wise combinations of the species were calculated by the same program. Such values represent the proportion of different bands between all the possible pairs of species.

\section{Results}

The RAPD technique was used to characterize the nine Pistacia species and clarify the relationships between them. A total of 242 fragments were generated by 20 arbitrarysequence primers, and 228 bands out of these were polymorphic at the inter-specific level. RAPD fingerprinting patterns of Pistacia genotypes using primer BC348 are shown as an example in Fig. 1. Data were analyzed using the PAUP program, to obtain cladograms that depict the likely relationship among the species. The two shortest trees were 338 steps long, and one of them is shown in Fig. 2. A $50 \%$ consensus-cladogram resulting from bootstrap analysis of the same data with 100 replicates is given in paranthesis. Pair-wise genetic distances between all the species were calculated by the same program (Table 2).

According to these cladograms, the nine Pistacia species are well separated from each other, and form two main groups or clusters. The two groups are separated by a branch of 14 steps, appearing in $99 \%$ of the bootstrap replicates. One group includes $P$. vera, $P$. khinjuk, $P$. eurycarpa, and $P$. atlantica, while $P$.

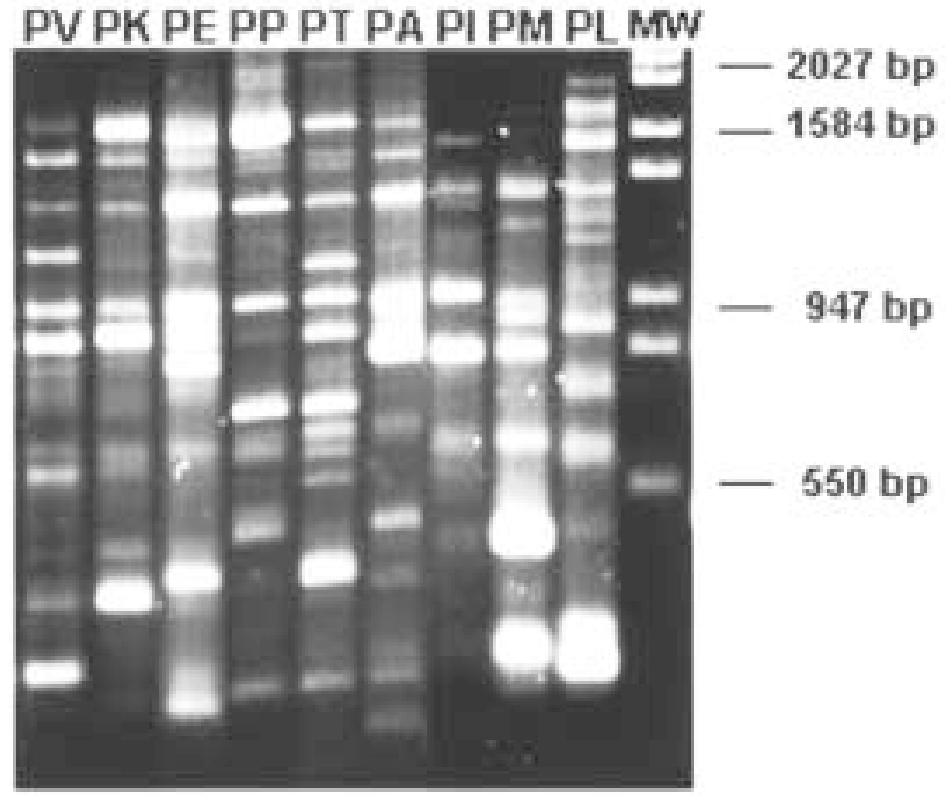

Fig. 1. RAPD banding patterns of nine Pistacia species using primer BC348. MW = molecular weight standards; the size of fragments is given in base pairs. $\mathrm{PV}=P$. vera, $\mathrm{PK}=P$. khinjuk, $\mathrm{PE}=P$. eurycarpa, $\mathrm{PA}=P$. atlantica, $\mathrm{PI}=P$. integerrima, $\mathrm{PP}=P$. palaestina, $\mathrm{PT}=P$. terebinthus, $\mathrm{PM}=P$. mexicana, $\mathrm{PL}=$ P. lentiscus.

terebinthus, $P$. palaestina, $P$. mexicana, and $P$. lentiscus are included in the second group. $P$. integerrima, however, does not cluster within any of the two groups and is wellseparated from both of them. The cladograms also show that $P$.terebinthus and $P$.palaestina are a close pair of species, as are $P$. eurycarpa and $P$. atlantica, $P$. vera and $P$. khinjuk, and $P$. mexicana and $P$. lentiscus. A branch of 20 steps appearing in $87 \%$ of the bootstrap replicates separates $P$. vera and $P$. khinjuk from the rest of the tree suggesting that, among the wild species, $P$. khinjuk is the closest relative of cultivated pistachio. A branch of 20 steps appearing in $78 \%$ of the bootstrap replicates separates $P$. eurycarpa and $P$. atlantica from $P$. vera and $P$. khinjuk, and all four species are separated by a branch of 13 steps, appearing in $100 \%$ replicates, from the rest of the tree.

\section{Discussion}

The most comprehensive studies concerning the taxonomic relationships between Pistacia species was performed by Zohary (1952) and, at the molecular level, by Parfitt and Badenes (1997). The former author subdivided the genus into four sections, whereas the latter ones subdivided it into two sections,
'Terebinthus' and 'Lentiscus'. According to the rules of botanical nomenclature presented in the International Code of Botanical Nomenclature (ICBN), any subgeneric taxon including the type species of a genus must be designated by the same name as the genus (the autonym). Thus, section 'Terebinthus' would, under the ICBN, becomes section Pistacia. The primary characters for taxonomic identification of Pistacia species were leaf rachis wing, leaflet size and shape, number of leaflet pairs, absence or presence of terminal leaflet, leaflet apex shape, nut size, and shape. Leaf rachis wing was one of the most discriminative characteristics used by Zohary (1952), who classified $P$. atlantica in a distinct Section, Butmela, on the basis of such character.

In our study, we obtained two groups of species: one group comprised $P$. vera, $P$. khinjuk, $P$. eurycarpa, $P$. atlantica, and $P$. integerrima; and the second group included $P$. terebinthus, $P$. palaestina, $P$. mexicana, and $P$. lentiscus. Considering their morphology, the species in the first group form big trees, whereas the second group tends to form small trees or shrubs. Parfitt and Badenes (1997) found that $P$. vera was more closely related to $P$. terebinthus than to $P$. integerrima. $P$. terebinthus trees in California grow as single, 


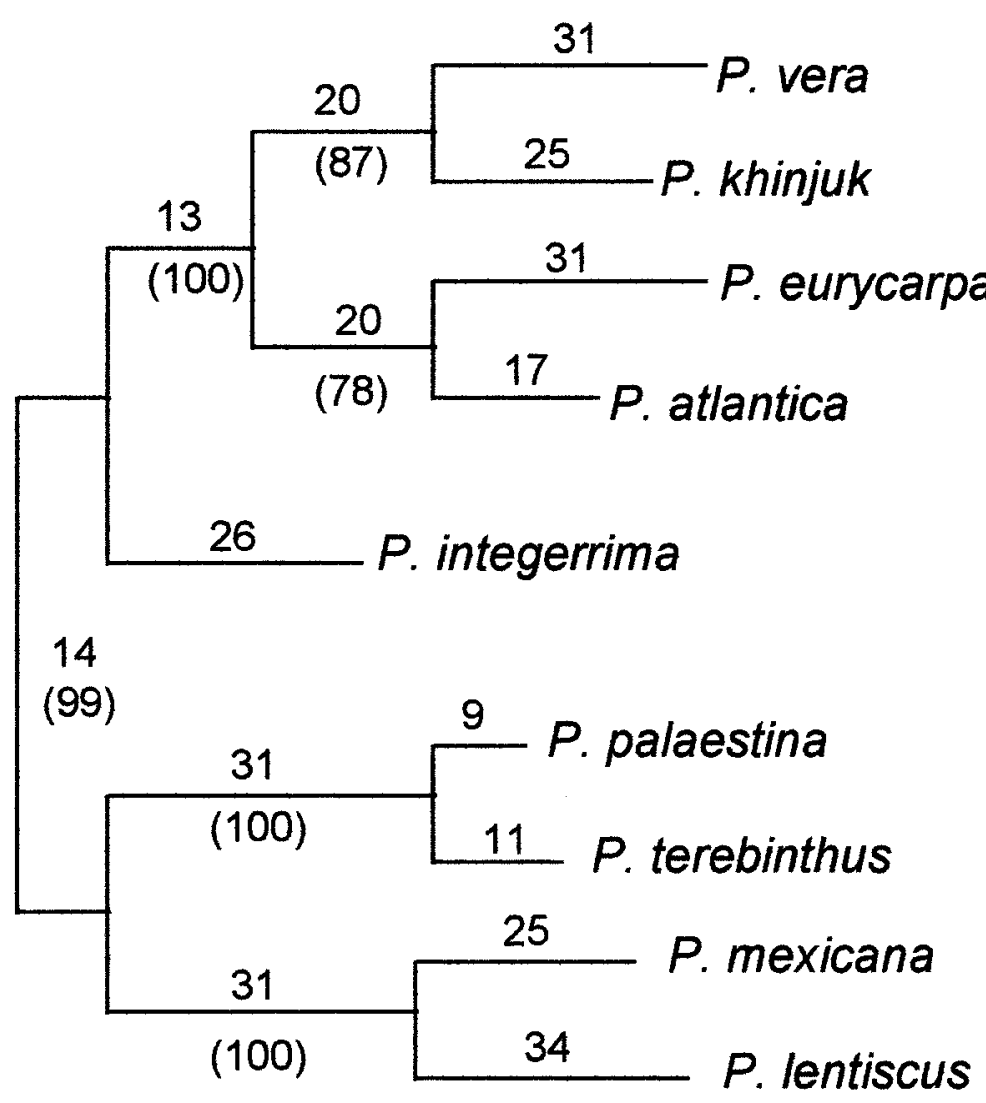

Fig. 2. Parsimony analysis of molecular fingerprinting data from nine Pistacia species. The database included 242 RAPD bands. A heuristic search was conducted by the PAUP software using TBR optimization, resulting in two trees of 338 steps. One of the trees is depicted. Numbers indicate the length (no. of steps) of each branch. Percentage values of a 50\% majority rule consensus tree obtained from 100 Bootstrap replicates of the same data are shown in parentheses.

Table 2. Pair-wise distances among Pistacia species $^{\mathrm{z}}$ calculated by PAUP program.

\begin{tabular}{lccccccccc}
\hline \hline & PV & PK & PE & PA & PI & PP & PT & PM & PL \\
\hline PV & --- & 0.227 & 0.264 & 0.285 & 0.364 & 0.455 & 0.450 & 0.504 & 0.550 \\
PK & & --- & 0.289 & 0.314 & 0.314 & 0.409 & 0.413 & 0.488 & 0.508 \\
PE & & & --- & 0.186 & 0.322 & 0.459 & 0.467 & 0.517 & 0.537 \\
PA & & & & -- & 0.244 & 0.393 & 0.409 & 0.463 & 0.479 \\
PI & & & & & --- & 0.277 & 0.293 & 0.351 & 0.376 \\
PP & & & & & & -- & 0.080 & 0.339 & 0.347 \\
PT & & & & & & & -- & 0.339 & 0.360 \\
PM & & & & & & & & -- & 0.240
\end{tabular}

PL

${ }^{2} \mathrm{PV}=P$. vera, $\mathrm{PK}=P$. khinjuk, $\mathrm{PE}=P$. eurycarpa, $\mathrm{PA}=P$. atlantica, $\mathrm{PI}=P$. integerrima, $\mathrm{PP}=P$. palaestina, $\mathrm{PT}=P$. terebinthus, $\mathrm{PM}=P$. mexicana, $\mathrm{PL}=P$. lentiscus

very large trees (D.E. Parfitt, 1997, personal communication). Whitehouse (1957) reported that, in California, $P$. terebinthus grows as a single-trunked tree and has a narrow leaf rachis wing. However, according to Zohary (1952) and to our observations under different ecological conditions, $P$. terebinthus usually grows as a shrub, rarely as a single tree, and never exhibits a leaf rachis wing. Ayfer and Serr (1961) also reported that $P$. terebinthus trees in California are similar to $P$. atlantica, based on tree and leaf characteristics, and may be a variety of $P$. atlantica. Therefore, we may conclude that the trees identified as $P$. terebinthus in California may have been misidentified, resulting in a close association of $P$. terebinthus with $P$. vera, $P$. khinjuk, and P. atlantica by Parfitt and Badenes (1997). We suggest that these trees are not true $P$. terebinthus, but a further study comparing Californian $P$. terebinthus samples with our Mediterranean sample is required to test this hypothesis.

In our study, $P$. terebinthus and $P$. palaestina formed a close pair, and they have sometimes been regarded as a single species. Engler who first classified Pistacia species, indeed considered $P$. palaestina as a variety of $P$.terebinthus (reviewed in Zohary, 1952). Zohary, however, considered $P$. palaestina as a distinct species, due to two main distinctive characteristics. $P$. palaestina has mostly paripinnate leaves and acuminate leaflets, while P.terebinthus has imparipinnate leaves and obtuse or acute leaflets. Yaltirik (1967a) described two subspecies within P. tere- binthus. The first, $P$. terebinthus subspecies terebinthus, had imparipinnate leaves with the terminal leaflet of the median leaves often as large as the lateral ones, and obtuse or ovate-oblong lateral leaflets. The second is $P$. terebinthus subsp. palaestina with either paripinnate and/or imparipinnate leaves, the terminal leaflet of the median leaves always smaller than the laterals or reduced to a bristle, and acuminate or oblong-lanceolate lateral leaflets. Our results support Engler's and Yaltirik's classifications. To confirm this hypothesis, we analyzed two additional $P$. terebinthus samples (from Southern and Western Turkey, respectively), and two additional $P$. palaestina samples (from Israel) using the same primers, and similar RAPD patterns were obtained between $P$. palaestina and $P$. terebinthus samples (data not shown). In our previous study (Kafkas and Perl-Treves, 2001), we also obtained similar pair-wise distances between accessions within a Pistacia species. All these suggest that the above leaf characters probably may not be sufficient to assign $P$. palaestina as a different species. Therefore, we find it more appropriate to consider $P$. palaestina as a variety of $P$. terebinthus.

Zohary (1952) classified P. eurycarpa as a variety of $P$. atlantica (var. kurdica) because of the presence of leaf rachis wing that narrower than in the type of $P$. atlantica. Yaltirik (1967b), on the other hand, treated this plant as a different species, because the leaves are light green on both sides (instead of being dark green above and pale below as in P.atlantica), and the nuts are depressed and bigger than in typical $P$. atlantica. Furthermore, the leaflets are usually thicker and never as numerous or narrow as in $P$. atlantica, and the leaf rachis wing is narrower or even absent. Kafkas and Perl-Treves (2001) retained P. eurycarpa as a different species by cluster analysis using both morphological and molecular data. This study also suggests that $P$. eurycarpa is closely related to $P$. atlantica but represents a distinct species, since the genetic distance between them is similar to the distance between other pairs of species.

\section{Literature Cited}

Al-Yafi, J. 1978. New characters differentiating Pistacia atlantica subspecies. Candollea 33:201208.

Ayfer, M. and E.F. Serr. 1961. Effect of $\mathrm{GA}_{3}$ and other factors and seed germination and early growth in Pistacia species. Proc. Amer. Soc. Hort. Sci. 77:308-315.

Dong, Z. and P. Baas. 1993. Wood anatomy of trees and shrubs from China. V. Anacardiaceae. IAWA J., 14 (1):87-102.

Doyle, J.J. and J.L. Doyle. 1987. A rapid isolation procedure for small quantities of fresh leaf tissue. Phytochem. Bul. 19:11-15.

El-Oqlah, A.A. 1996. Biosystematic research on the genus Pistacia in Jordan, p. 12-19. In: S. Padulosi, T. Caruso, and E. Barone(eds.). Taxonomy, distribution, conservation and uses of Pistacia genetic resources IPGRI, Palermo, Italy.

FAO, 2000. FAO web page. (http://www.fao.org) Grundwag, M. and E. Werker. 1976. Comparative 
wood anatomy as an aid to identification of Pistacia L. species. Israel J. of Bot., 25:152-167.

Hormaza, J.I., L. Dollo, and V.S. Polito. 1994 Determination of relatedness and geographic movements of Pistacia vera (Pistachio; Anacardiaceae) germplasm by RAPD analysis Econ. Bot. 48:349-358.

Hormaza, J.I., K. Pinney, and V.S. Polito. 1998. Genetic diversity of pistachio (Pistacia vera, Anacardiaceae) germplasm based on randomly amplified polymorphic DNA (RAPD) markers. Econ. Bot. 52:78-87.

Kafkas, S. and R. Perl-Treves. 2001. Morphological and molecular phylogeny of Pistacia species in Turkey. Theor. Appl. Genet. 102:908-915.

Kokwaro, J.O. and J.B. Gillett. 1980. Notes on the Anacardiaceae of Eastern Africa. Kew Bul. 34:745-760

Lin, T.S., J.C. Crane, K. Ryugo, V.S. Polito, and
T.M. Dejong. 1984. Comparative study of leaf morphology, photosynthesis and leaf conductance in selected Pistacia species. J. Amer. Soc. Hort. Sci. 109:325-330.

Louskas, M. and C.A. Pontikis. 1979. Pollen isozyme polymorphism in types of Pistacia vera and related species as aid in taxonomy. J. Hort. Sci. 54:95-102.

Maggs, D.H. 1973. Genetic resources in pistachio. Plant Genetic Resources Nwsl., 29:7-15.

Parfitt, D.E. and M.L. Badenes. 1997. Phylogeny of the genus Pistacia as determined from analysis of the chloroplast genome. Proc. Natl. Acad. Sci. 94:7987-7992.

Swofford, D.L. 1993. PAUP: Phylogenetic analysis using parsimony, version 3.1, Computer program distributed by the Illinois natural history survey, Campaign, Ill.

Whitehouse W.E. 1957. The pistachio nut-A new crop for the Western United States. Econ. Bot. 11:281-321.

Williams, J.G.K., A.R. Kubelik, K.J. Livak, J.A. Rafalski, and S.V. Tingey. 1990. DNA polymorphism amplified by arbitrary primers are useful as genetic markers. Nucl. Acids Res. 18:6531-6535.

Yaltirik, F. 1967a. Anacardiaceae. In: Davis P.H. (ed). Flora of Turkey 2:544-548.

Yaltirik, F. 1967b. Anacardiaceae. Contributions to the taxonomy of woody plants in Turkey. Notes from the Royal Botanic Garden Edinburgh, 28:11-12.

Zohary, M. 1952. A monographical study of the genus Pistacia. Palestine J. of Bot. Jerusalem Series, 5:187-228.

Zohary, M. 1972. Pistacia L. Flora Palestine, Israel Acad. of Sci. and Humanities, Jerusalem, 2:297300. 